\title{
Comparison of coronary angioplasty with medical treatment for single- and double-vessel coronary disease with left anterior descending coronary involvement: Long-term outcome based on an Emory-CASS registry study
}

\begin{abstract}
The 3 to 5-year clinical outcomes of 627 consecutive patients selected for treatment with percutaneous transluminal coronary angioplasty (PTCA) at Emory University Hospital for one- or two-vessel coronary artery disease with involvement of the left anterior descending coronary artery, between July 1981 and June 1983 , and 865 patients in the Coronary Artery Surgery Study with similar coronary artery disease involvement selected for medical therapy between 1975 and 1979 were compared. Cox analyses and stratified life table analyses were used to adjust for differences in 13 variables including concurrent medical therapy. Complete follow-up was obtained in $97 \%$ of PTCA patients and $99 \%$ of medically treated patients. After correction for baseline differences in significantly predictive variables, there was no difference between the relative risk of death after PTCA vs medical therapy ( $R R=0.7 ; p=0.36)$. However, results of analysis of prospectively defined subsets showed a potential survival benefit after PTCA for patients with an ejection fraction $<50 \%(R R=0.2 ; p=0.02)$ and also for patients with two-vessel disease (RR $=0.2 ; p=0.04)$. For the groups as a whole there was no difference in risk of infarction after PTCA and medical therapy $(\mathrm{RR}=0.8 ; p=0.58)$. However, for patients with $90 \%$ to $99 \%$ LAD stenosis there was a trend toward lessened risk of infarction after PTCA $(R R=0.6 ; p=0.15)$. No patient subset had a higher risk of death or infarction with PTCA $(p \leq 0.15)$. The likelihood of later surgery was increased after PTCA (RR $-1.5 ; p-0.002)$. Angina, employment, and activity levels were improved after PTCA. Thus PTCA compared to medical therapy was associated with improved functional status and may decrease the risk of death and infarction in certain patient subsets. However, bypass surgery was more often performed in patients initially treated with PTCA. These data should be interpreted in light of their nonrandomized study origin and generation from different clinical sites. (AM HEART J 1989; 118:208.)
\end{abstract}

Stephen G. Ellis, MD, Lloyd Fisher, PhD, Sandra Dushman-Ellis, MHSA, Mary Pettinger, BS, Spencer B. King III, MD, Gary S. Roubin, MB, PhD, and Edwin Alderman, $\mathrm{MD}$, with the technical assistance of Judy Evans.

Atlanta, Ga., Seattle, Wash., and Ann Arbor, Mich.

The survival of patients with coronary artery disease and medical treatment has been reported from multiple studies to be related to left ventricular function

From the Andreas Gruentzig Cardiovascular Center, Departments of Medicine and Radiology, Emory University School of Medicine, the Coordinat ing Center for Collaborative Studies in Coronary Artery Surgery, University of Washington, and the Department of Internal Medicine, Division of Cardiology, University of Michigan Medical Center.

The CASS Principal Investigators and their associates are listed in Appendix I.

Received for publication Feb. 7, 1989; accepted March 15, 1989.

Reprint requests: Stephen G. Ellis, MD, University of Michigan Medical Center, Room B1 F245, 1500 M. Medical Center Dr., Ann Arbor, MI 48109 0022 . and to the extent of coronary disease, usually measured as the number of diseased vessels. ${ }^{1-4}$ In addition, disease involvement of the left anterior descending coronary artery (LAD) may increase mortality beyond that expected based on the number of diseased vessels alone, ${ }^{5,6}$ presumably because it supplies more left ventricular mass than the other coronary arteries. ${ }^{7}$ Specifically, disease limited to the LAD is associated with mortality rates 1.5 to 5 times that of disease limited to the other major epicardial coronary arteries..$^{8-11}$ Prognosis may be especially poor and impairment of left ventricular function may be especially severe when significant stenoses are lo- 
cated proximal to the first major septal perforator of the LAD. 7, 12-15 Two-vessel coronary artery disease with LAD involvement also has a worse prognosis than two-vessel coronary disease without LAD involvement. $6,7,16$

Surgical revascularization improves survival in patients with coronary artery disease who have left main disease and three-vessel disease with moderate ventricular impairment or severe angina despite medical therapy. In addition, results from the European Cooperative Study ${ }^{16}$ suggest that survival in patients with two-vessel and proximal LAD involvement may be improved in comparison with results of medical therapy, as does the Coronary Artery Surgery Study (CASS) registry for patients with twovessel involvement, class $\geq 3$ angina, impaired ventricular function, and narrowing of at least one proximal coronary artery. ${ }^{17}$ Coronary artery bypass grafting has not been shown to increase survival in any subset of patients with single-vessel disease or with other subsets of patients with two-vessel coronary disease. ${ }^{16,18}$ Furthermore, bypass grafting has not been shown to decrease the rates of myocardial infarction in any anatomic subgroup. ${ }^{19}$

An alternate form of revascularization, percutaneous transluminal coronary angioplasty (PTCA), has been widely recommended and applied for the treatment of symptomatic single-vessel and more recently multivessel coronary disease. Although angioplasty is angiographically successful in $90 \%$ of selected patients $^{20-22}$ and is usually associated with clinical improvement, ${ }^{23}$ a benefit in terms of improved survival and lessened risk of infarction has not been demonstrated. Several major randomized clinical trials have recently been undertaken to address the appropriate role of PTCA in the management of patients with coronary disease. Results from these studies will not be forthcoming until the 1990s. In such a circumstance the examination of clinical results obtained from large, carefully defined, and matched patient populations, adjusted for differences in baseline variables, is the best method of defining the efficacy of a given intervention in the interim. ${ }^{24}$ Accordingly we compared the 3 to 5 -year results of medical and PTCA treatment of patients with one- and two-vessel coronary disease and involvement of the LAD by means of the comprehensive CASS and Emory University Hospital PTCA data bases to better define the role of PTCA in the management of patients with coronary disease.

\section{METHODS}

Patient sources - angioplasty. From July 1980 through December 1985, a total of 5290 patients underwent PTCA at Emory University Hospital. Although there is no record of the total number of patients referred to Emory for con- sideration for PTCA, probably one quarter of the number of patients accepted into this study who also had single- or double-vessel disease with involvement of the LAD were refused PTCA during the same time period because they were thought to be technically unsuitable or at "high risk" for complications of the procedure. Since June 1981, the primary success rate for LAD dilatation has been relatively stable and has exceeded $90 \%$. The primary success rate was lower during the time period before May 1981, and this period has been described as the "learning period". ${ }^{25}$ To allow maximum time of follow-up at current levels of efficiency, the time period July 1981 through June 1983 was arbitrarily chosen for patient entry. During this time period 914 patients had elective PTCA of the LAD, of whom 754 had single-vessel disease (defined as stenosis limited to one major epicardial vessel compromising $\geq 50 \%$ of the normal lumen diameter by visual inspection) and 160 had double-vessel disease.

Patient sources-medical treatment. The CASS is a multiinstitutional research project consisting of a randomized trial of the medical vs surgical treatment of coronary artcry discase and a larger registry of patients who underwent diagnostic evaluation including coronary angiography for suspected coronary disease and were followed for subsequent cardiac events. ${ }^{26}$ Between August 1975 and May 1979 , a total of 24,179 patients underwent arteriography for suspected coronary artery disease and were entered in the CASS registry study. Of these 5594 had documented single- or double-vessel LAD disease. Based on physician and patient preference, 290 of these patients were randomized to either medical or surgical therapy. ${ }^{26}$ Of the patients that were not randomized, 3115 patients were treated initially with medical therapy and 2189 patients received initial surgical therapy. Patients treated with initial medical therapy were eligible for this study. Of these $54 \%$ of patients were treated with nitrates alone, $42 \%$ also received beta blockers, and $6 \%$ received antiplatelet agents.

Eligibility criteria. All medically treated patients in the CASS registry and all PTCA patients in the Emory University Hospital study (except as noted previously) who met the following inclusion and exclusion criteria were entered into the analysis.

Inclusion criteria. Patients were included for the following reasons: (1) Single- or double-vessel disease ( $\geq 50 \%$ diameter stenosis in a major epicardial vessel); (2) $50 \%$ to 99\% stenosis in the LAD or a major diagonal branch; (3) Canadian Heart Association class I to IV angina; (4) known use or nonuse of beta blockers and calcium channel blockers (to allow comparison of medical therapies); and (5) for the PTCA group only, angioplasty performed at one or more sites of LAD stenosis (with or without dilatation of other vessels).

Exxclusion criteria. Patients with akinesis or dyskinesis of the anterobasal, anterolateral, or apical segments on baseline the right anterior ublique ventriculogram were excluded.

Angioplasty technique and follow-up. The technique of PTCA has been described elsewhere. ${ }^{27}$ All procedures were performed by one of three highly experienced independent operators (A.R.G., S.B.K., or J.S.D.). After PTCA the pa- 
Table I. Baseline patient characteristics

\begin{tabular}{lcc}
\hline \multicolumn{1}{c}{ Characteristics } & $\begin{array}{c}\text { Medical } \\
\text { therapy }\end{array}$ & $\begin{array}{c}\text { Initial PTCA } \\
\text { therapy }\end{array}$ \\
\hline No. of patients & 865 & 627 \\
Age (yr; mean \pm SD) & $53 \pm 9$ & $54 \pm 10$ \\
Sex (\% male) & 74.1 & 75.0 \\
Angina class (\%) & & \\
I & 9.6 & 16.6 \\
II & 46.6 & 41.7 \\
III & 34.6 & 29.8 \\
IV & 9.2 & 11.9 \\
Unstable angina (\%) & 42.6 & 48.9 \\
Employment status & & \\
Full time & 56.4 & $68.6 \ddagger$ \\
Part time & 9.7 & 5.7 \\
Retired & 10.2 & 14.8 \\
Medically retired & 15.6 & 7.4 \\
Other & 8.1 & 3.6 \\
Number of diseased vessels* & & \\
One & 41.7 & $83.3 \S$ \\
Two & 58.3 & $16.7 \S$ \\
Maximum \% LAD stenosis $\dagger$ & & \\
50-69\% & 37.8 & $20.0 \S$ \\
70-89\% & 35.4 & $55.2 \S$ \\
90-99\% & 26.8 & 24.8 \\
Proximal LAD stenosis (\%) & 24.5 & $35.1 \S$ \\
Left ventricular ejection & $65 \pm 12$ & $61 \pm 8$ \\
fraction (\%) & & \\
Duration of follow-up (mo) & $58 \pm 17$ & $42 \pm 8 \ddagger$ \\
\end{tabular}

${ }^{*}<50^{\circ ;}$ narrowing of a major epicardial vessel (see Methods). $\uparrow V$ isually determined.

$\ddagger p \leq 0.001$ by chi-square analysis.

$\S p \leq 0.01$ by chi-square analysis.

tients were taken to a postprocedure monitoring ward or to the coronary care unit where they were maintained on telemetry for 12 to 24 hours after angioplasty. A 12-lead ECG was obtained immediately after PTCA and daily for 2 days. Creatine kinase levels, including isoenzyme determinations, were performed immediately after PTCA and at 8 and 16 hours. All patients were medicated with transcutaneous nitroglycerin, an oral calcium-blocking agent, and aspirin. If stable, patients were discharged 2 days after PTCA.

Clinical, angiographic, and PTCA data, including ECG and cardiac enzyme information, were recorded during hospitalization by physicians on standard forms and stored in a data base with the use of a VAX-11/750 computer. Medical records, catheterization charts and, when necessary and available, the relevant cineangiograms of all patients undergoing single- or double-vessel PTCA of the LAD were reviewed to assure completeness and accuracy of this data base. One hundred thirty-three patients were eliminated from this analysis because of incomplete data (age, sex, number of diseased vessels, location, and percentage diameter stenosis of all stenoses in the LAD and other vessels, pre-PTCA left ventricular ejection fraction, Canadian Heart Association angina class, presence or absence of unstable angina, and pre-PTCA use of beta block- ers, calcium channel blockers, and antiplatelet agents). Elimination of a patient was most often necessary because only the diseased vessel was visualized during the PTCA procedure, and confirmation from referral angiograms of the severity of disease in other vessels or left ventricular function was not always available. In addition, 96 patients who had previously undergone bypass surgery and 58 patients with a totally occluded LAD were eliminated.

All patients treated with angioplasty were contacted by phone by trained technicians, nurses, or physicians after January 1, 1986. Follow up data were recorded on a standard form designed to match that used for follow-up of patients in the CASS. ${ }^{26}$ Patients or their relatives were questioned for the occurrence and dates of myocardial infarction, coronary artery bypass surgery, additional PTCA, level of angina, occupational and activity levels, type of medical therapy, and vital status. Personal physicians were contacted when necessary to verify the cause of death and the nature of the chest pain and to provide documentation of myocardial infarction in all suspected infarctions and in all hospitalizations of more than 5 days' duration. In addition, ECGs were requested on $5 \%$ of randomly selected patients (as was done in the CASS registry). Follow-up for $\geq 30$ months was 97 complete. Data were entered in a VAX-11/750 computer for analysis.

Follow-up of medically treated patients. Annual clinical follow-up was mandatory for all patients involved in the CASS registry. Follow-up information was usually collected by telephone interview or via mailed questionnaire ${ }^{26}$ and was recorded on standardized forms. In addition, ECGs were required periodically from a randomized subset of patients in the registry. Further clinical details were obtained in the event of suspected myocardial infarction, hospitalization for more than 5 days, and cardiac surgery or death. Follow-up for $\geq 30$ months was $98 \%$ complete. All data were recorded for entry into the computer.

\section{Definition of terms}

Angina status. The patient's average or typical level of chest discomfort during the 4 to 6 weeks before entry into the study and during the interval before each annual follow-up was classified as follows: (1) class $I=$ chest pain only with strenuous or prolonged physical activity; (2) class II = chest pain with rapid or moderate to extensive walking or stair climbing (more than two blocks or more than one flight) or in cold or wind or when under emotional stress; (3) class $\mathrm{III}=$ chest pain with minimal walking or stair climbing, such as walking two level blocks or less or climbing one flight of stairs or less at a normal pace under normal conditions; (4) class IV $=$ chest pain with any level of physical activity or even at rest. In the event of a question as to the nature of the patient's symptoms, ancillary evidence such as response to nitroglycerin or results of a recent exercise treadmill examination were obtained.

Complete revascularization. This was anatomically defined as restoration of patency (diameter stenosis $<50 \%$ ) to all $\geq 2 \mathrm{~mm}$ vessels subserving apparently viable myocardium (associated ventriculographic wall motion not akinetic or dyskinetic).

Employment status. Each patient's employment status 
Table II. Impact of therapy on survival

\begin{tabular}{|c|c|c|c|c|}
\hline Subgroup* & $N \dagger$ & $\begin{array}{c}\text { Variables entering multivariate } \\
\text { analysis }(p<0.05)\end{array}$ & $\begin{array}{c}\text { Relative risk } \\
\text { of death } \\
\text { (PTCA/Medical therapy) } \neq\end{array}$ & $\begin{array}{l}p \text { Value for } \\
\text { therapy } \ddagger\end{array}$ \\
\hline Overall & 1,407 & $\begin{array}{l}\text { No. of diseased vessels, baseline } \\
\text { activity level }\end{array}$ & $0.7(0.3-1.5)$ & 0.36 \\
\hline Single vessel & 821 & Maximum LAD \% stenosis & $1.2(0.5-2.8)$ & 0.71 \\
\hline Double vessel & 586 & Baseline activity level & $0.2(0.2-1.3)$ & 0.04 \\
\hline Proximal LAD stenosis & 482 & No. of diseased vessels & $0.5(0.1-2.4)$ & 0.40 \\
\hline No proximal LAD stenosis & 925 & Maximum LAD \% stenosis & $0.8(0.3-1.5)$ & 0.39 \\
\hline LVEF $<50 \%$ & 126 & Baseline angina class & $\S$ & 0.02 \\
\hline $\mathrm{LVEF} \geq 50 \%$ & 1,281 & $\begin{array}{l}\text { No. of diseased vessels, age, maximum } \\
\text { LAD } \% \text { stenosis }\end{array}$ & $0.8(0.4-1.6)$ & 0.50 \\
\hline Stable angina & 756 & $\begin{array}{l}\text { No. of diseased vessels, age, baseline } \\
\text { angina class }\end{array}$ & $0.5(0.2-1.5)$ & 0.22 \\
\hline Unstable angina & 648 & No. of diseased vessels & $0.7(0.3-1.9)$ & 0.53 \\
\hline
\end{tabular}

*Prospectively defined.

†Total number of PTCA and medically treated patients with known data for all variables achieving univariate $p \leq 0.05$ as predictors of outcome. †After correction for differences in baseline variables in the Cox model; $95 \%$ confidence intervals given in parentheses.

$\S$ No patients died after PTCA.

at the time of entry into the study and at follow-up was classified as follows: (1) full time indicates the patient was working an average of 40 hours per week or more; (2) part time indicates the patient was continuously or nearly continuously employed but working an average of less than 40 hours per week; (3) retired indicates the patient had stopped working after reaching retirement age as opposed to quitting because of physician's advice, incapacitation, or fear; (4) medically retired indicates that the patient was forced to retire before retirement age because of cardiac symptoms with or without recommendation of a physician; (5) other indicates that the patient was unemployed (by economic circumstances or choice), on temporary sick leave, or was disabled, as a result of a noncardiac illness.

Initially successful PTCA. This was defined as a reduction of all or of the most important stenosis (es) to $<50 \%$ residual diameter stenosis, with clinical improvement and without myocardial infarction or bypass surgery during hospitalization.

Myocardial infarction. This was defined clinically as definite or probable infarction based on the development of new diagnostic $\mathrm{Q}$ waves on the $\mathrm{ECG},{ }^{28}$ elevation of cardiac enzymes ( $\geq 3$ times upper limit of normal range), or both.

Number of vessels diseased. The number of vessels diseased was defined as the number of major epicardial coronary vessels (left anterior descending, left circumflex, and right coronary artery) or major branches thereof that had a least one stenosis reducing the lumen by at least $50 \%$ compared to the adjacent normal vessel. (Note: this definition varies from that in most CASS registry studies, which use $>70 \%$. $)^{29}$

Partial revascularization. This was defined as revascularization of one or more $\geq 2 \mathrm{~mm}$ vessels supplying apparently viable myocardium but not all such vessels.

PTCA site. The PTCA site(s) was defined by means of standard CASS nomenclature. ${ }^{26}$
Activity level. The patient's daily recreational or physical activity level at the time of entry into the study and during the interval since the last follow-up examination was classified as strenuous, moderate, mild, or sedentary. These descriptors referred to activities in addition to regular employment/homemaking. If the patient was retired the descriptor referred to all daily activities. Examples of strenuous activity included a second job including heavy physical labor, heavy housework, or physically demanding recreational activities usually involving competition, endurance, and/or team effort. Examples of moderate activity included a second job requiring moderate manual labor or recreational activities performed for pleasure and relaxation without ideas of competition, endurance, or excellence in them. Examples of mild activity included light housework or recreational activities involving only slight physical activity. Examples of sedentary activity included a second job that did not require physical exertion or recreational activities that could be done while sitting.

Unstable angina. The definition of unstable angina included new or progressive angina within 2 months before entry into the sludy and angina that occurred with minimum activity and/or at rest.

Statistical analysis. Comparison of the baseline characteristics of the PTCA and medically treated groups was performed with unpaired Student's $t$ tests for continuous variables and the chi-square test for catagoric variables.

All analyses of results were performed at the CASS coordinating center. Determinants of death, myocardial infarction, bypass surgery, and angina, employment, and activity levels were defined by means of Cox proportional hazards linear regression analysis. Comparisons of treatment outcomes were performed with Cox analyses and also with life-table analyses, stratifying for variables that were significant in the multivariate Cox analysis. All results reported are from the former method of analysis unless otherwise specified. 
Table III. Impact of therapy on rates of nonfatal myocardial infarction

\begin{tabular}{|c|c|c|c|c|}
\hline Subgroup* & $N+$ & $\begin{array}{l}\text { Variables entering } \\
\text { multivariate analysis }\end{array}$ & $\begin{array}{c}\text { Relative risk } \\
\text { of infarction } \\
\text { (PTCA/Medical } \\
\text { therapy) } \ddagger\end{array}$ & $\begin{array}{l}\text { p Value } \\
\text { for } \\
\text { therapyt }\end{array}$ \\
\hline Overall & 1,343 & $\begin{array}{l}\text { No. of diseased vessels, maximum } \\
\text { LAD \% stenosis, age, baseline } \\
\text { activity level }\end{array}$ & $0.8(0.5-1.3)$ & 0.58 \\
\hline \multicolumn{5}{|c|}{ Maximum LAD \% stenosis } \\
\hline $50-69 \%$ & 421 & No variables achieved $p \leq 0.12$ & $1.0(0.4-2.6)$ & 0.94 \\
\hline $70.89 \%$ & 599 & LVEF & $1.1(0.6-2.2)$ & 0.74 \\
\hline $90-99 \%$ & 351 & $\begin{array}{l}\text { No other variables } \\
\text { achieved } \rho \leq 0.22\end{array}$ & $0.6(0.3-1.2)$ & 0.15 \\
\hline Stable angina & 747 & Maximum LAD $\%$ stenosis & $0.8(0.5-1.4)$ & 0.47 \\
\hline Unstable angina & 621 & Sex & $1.0(0.5-1.9)$ & 0.98 \\
\hline
\end{tabular}

*Prospectively defined.

†Total number of PTCA and medically treated patients with known data for all variables achieving univariate $p \leq 0.05$ as predictors of outcome. $\ddagger$ After correction for differences in baseline variables in the Cox model.

Table IV. Impact of therapy on angina, employment, and activity levels at 3-year follow-up*

\begin{tabular}{|c|c|c|c|c|}
\hline End point & $N$ & $\begin{array}{c}\text { Variables entering multivariate } \\
\text { analysis }(p<0.05)\end{array}$ & $\begin{array}{l}\text { Therapy with } \\
\text { better outcome }\end{array}$ & $\begin{array}{l}p \text { Value for } \\
\text { therapyt }\end{array}$ \\
\hline Angina class & 1,358 & $\begin{array}{l}\text { Maximum LAD } \\
\text { angina status, baseline activity } \\
\text { level, LVEF }\end{array}$ & PTCA & $\leq 0.001$ \\
\hline Employment status & 615 & $\begin{array}{l}\text { Baseline employment status, age, } \\
\text { sex, baseline activity lcvel, } \\
\text { baseline angina class }\end{array}$ & P'TCA & $\leq 0.001$ \\
\hline Activity level & 1,311 & $\begin{array}{l}\text { Maximum LAD } \% \text { stenosis baseline } \\
\text { angina class, LVEF }\end{array}$ & PTCA & $\leq 0.001$ \\
\hline
\end{tabular}

*Log linear model at 3-year follow-up.

†After correction for differences in baseline variables in the log linear model.

\$Patients retired at baseline or at age $\geq 65$ at 3 -year follow-up were not included in the analysis.

The following baseline variables were entered into the multivariate analyses: age, use of antiplatelet, betablocking, and calcium channel-blocking agents, Canadian Heart Association angina class, left ventricular ejection fraction (by right anterior oblique ventriculography), employment status (full time, part time, retired, medically retired, other), proximal LAD stenosis ( $\geq 50 \%$ diameter stenosis by visual inspection before the first major septal perforator), maximum percentage of LAD stenosis (by visual inspection), activity level (sedentary, mild, moderate, strenuous based on previous definitions), sex, stable or unstable angina, number of diseased vessels ( $\geq 50 \%$ diameter stenosis of a major epicardial vessel), and PTCA site (Table I). Results are expressed as: (1) relative risk of the outcome (PTCA/medical treatment) such that a relative risk of one implies no relative benefit for either therapy and a value of less than one suggests a benefit from PTCA (Tables II to IV); (2) two-tailed covariate $p$ value from the Cox proportional hazards linear regression analysis (Tables II to IV); and (3) two-tailed $p$ value for the treatment variable after pooling over all strata in the life-table analysis (Figs. 1 to 4$)$.

\section{RESULTS}

Patient characteristics. The clinical and angiographic characteristics of the 865 patients treated medically and the 627 patients treated with initial PTCA are shown in Table I. Both groups were largely made up of and equivalent in the percentage of middle-aged men with mild-to-moderate but often unstable angina and well-preserved left ventricular contractility. The PTCA group had more patients with proximal LAD stenoses $(35.1 \%$ vs $24.5 \%$; $p \leq 0.01)$, more patients with moderate or severe stenoses $(80.0 \%$ vs $61.2 \% ; p \leq 0.01)$, and fewer patients with two-vessel disease $(16.7 \%$ vs $58.3 \%$; $p \leq 0.01$ ). In addition, more PTCA patients were employed full time and could perform strenuous levels of physical activity.

Medical therapy. The medical treatment for the two groups differed. Although approximately the same percentage of patients from each group was treated with beta blockers (medical group $42.0 \%$, PTCA 


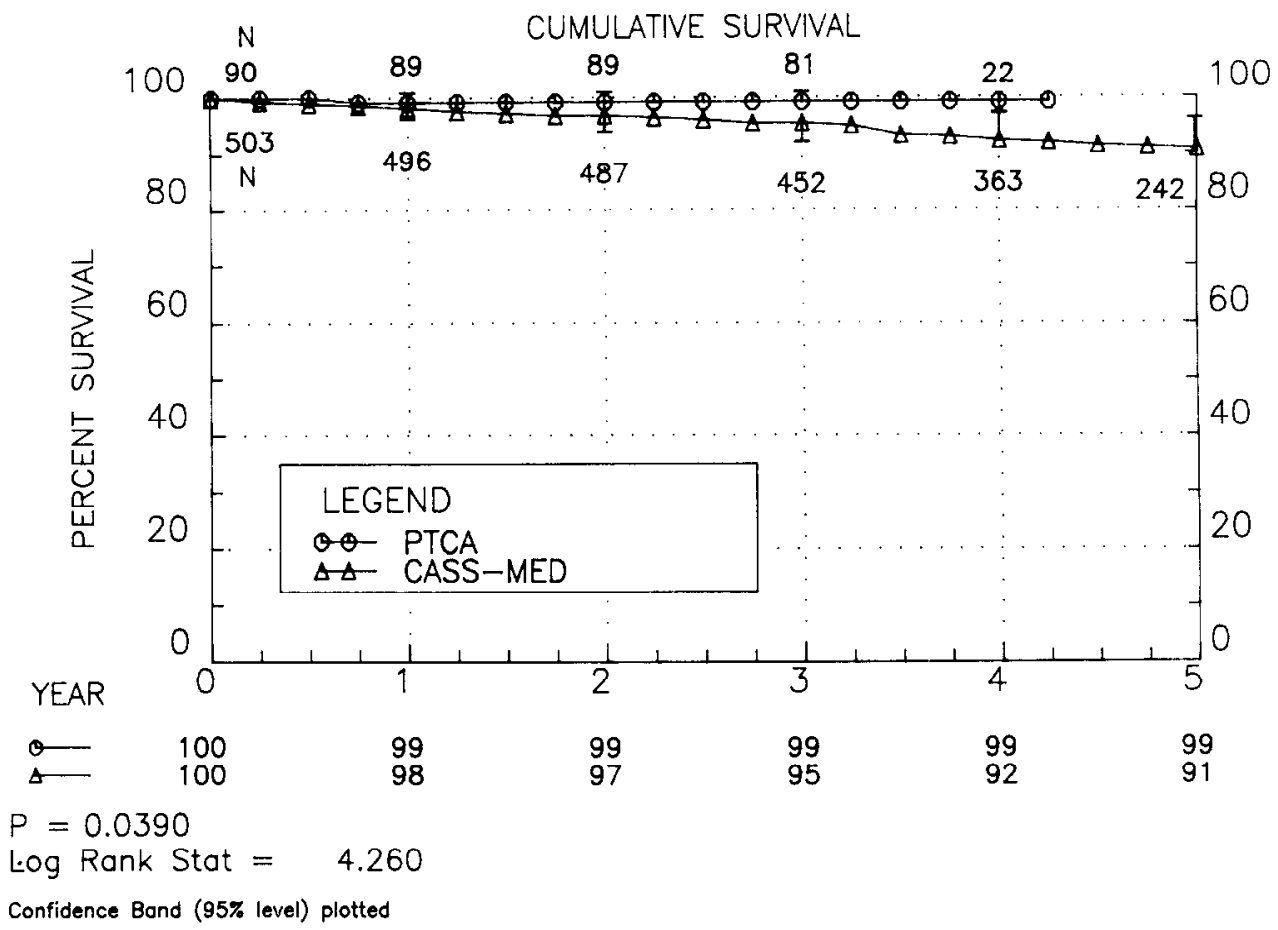

Fig. 1. Life-table analysis of cumulative survival for patients with baseline left ventricular ejection fraction $<0.50$ after adjustment for differences in baseline angina class.

group $32.8 \% ; p=\mathrm{NS}$ ), more patients in the medical group received long-acting nitrates $(56.5 \%$ vs $19.5 \%$ $p \leq 0.01$ ), whereas more patients in the PTCA group received antiplatelet agents $(70.9 \%$ vs $6.1 \%$; $p \leq 0.001)$. The use of calcium channel-blocking agents was not recorded during the follow-up of the medically treated patients, since they were not available in this country when the CASS trial began. Thirty-nine percent of the PTCA patients received calcium channel blockers during the 1 to 5 -year follow-up.

Initial PTCA results. For the PTCA group as a whole there was a $91.8 \%$ rate of initial procedural success, a $4.1 \%$ rate of emergency bypass surgery, and a $1.4 \%$ incidence of procedure-related myocardial infarction. These results did not differ significantly for patients with single- or double-vessel disease or by the percentage of LAD stenosis. There were no inhospital deaths.

Long-term survival. Results of survival analyses for both groups of patients, and for certain prospectively defined patient subgroups, after correction for differences in significant baseline variables are shown in Table II. The 5-year actuarial survival for all patients treated medically did not differ from that for all patients treated initially with angioplasty $(93 \%$ vs $95 \%$; $p=0.36$ ). However, patients with baseline left ven- tricular ejection fraction less than $50 \%$ (4-year survival rate of $86 \%$ vs $100 \% ; p=0.02$ ) benefitted from angioplasty, as may have patients with two-vessel disease (4-year survival rate of $93 \%$ vs $99 \% ; p=0.04$ ) (Figs. 1 and 2). No subgroup of patients had a decrease in survival rate $(p \leq 0.20)$ with PTCA.

Long-term freedom from nonfatal myocardial infarction. The 5-year actuarial rate of nonfatal myocardial infarction was $12 \%$ for the PTCA group and $10 \%$ for the medically treated group ( $p=\mathrm{NS}$ ). The impact of therapy on the rates of myocardial infarction after correction for differences in significant baseline variables for the groups as a whole and for certain subgroups is shown in Table III. Although there was no difference in overall outcome, results of Cox analysis disclosed a trend toward a decreased incidence of infarction when PTCA was performed in patients whose worst LAD stenosis was $90 \%$ to $99 \%$. For patients with $90 \%$ to $99 \%$ stenoses the difference in outcome was not significant (relative risk of infarction for PTCA compared to medical therapy $=0.6$, $95 \%$ confidence limits $=0.3$ to $1.2 ; p=0.15$ ), but PTCA therapy was the most important predictor of outcome. The 4-year actuarial nonfatal infarction rates for patients with $50 \%$ to $69 \%$ and $70 \%$ to $89 \%$ stenoses were $6.2 \%$ vs $6.5 \%$ and $5.6 \%$ vs $6.5 \%$ for the medically treated and PTCA patients, respectively. 


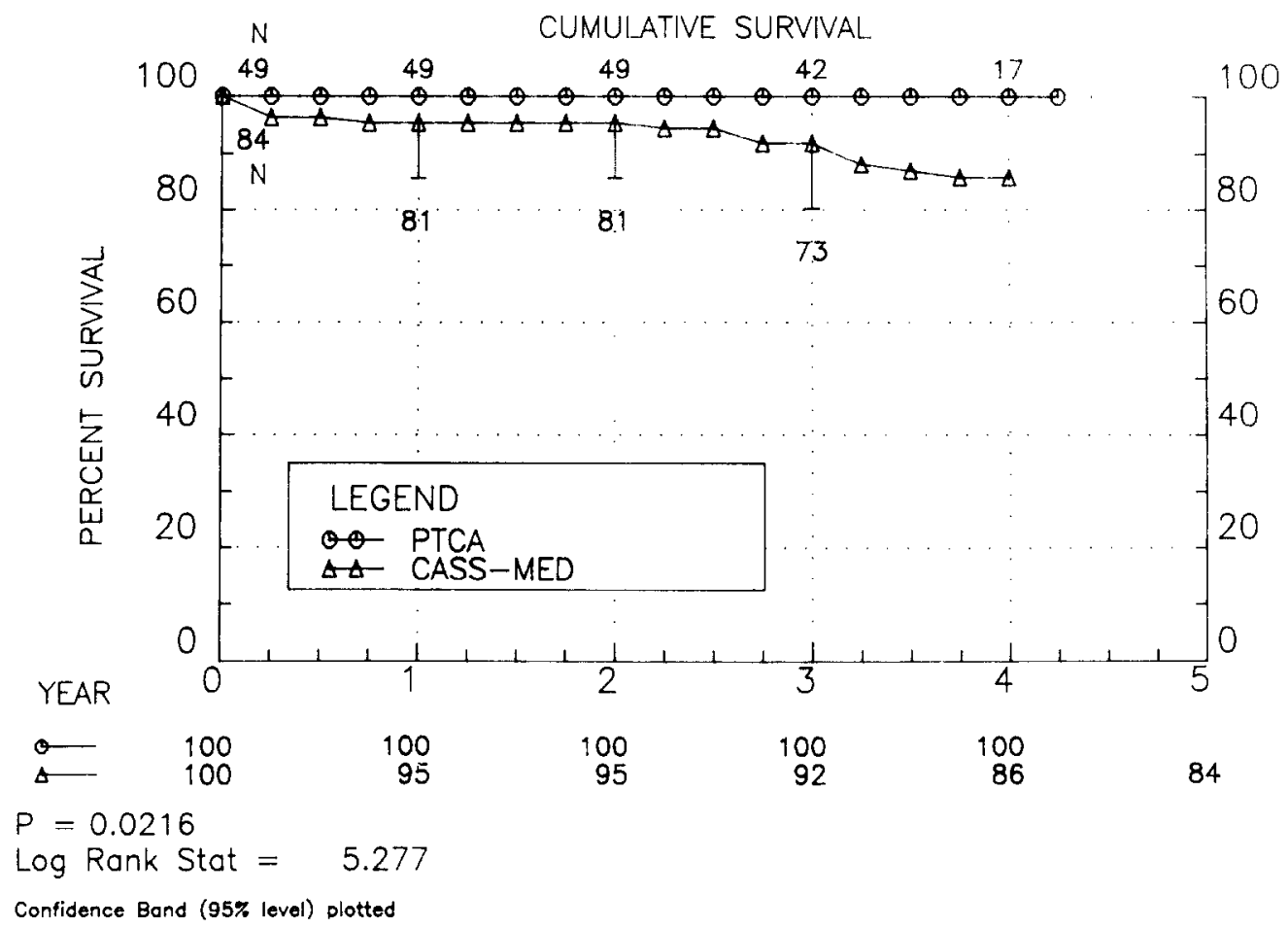

Fig. 2. Life-table analysis of cumulative survival for patients with two-vessel disease after adjustment for differences in baseline activity levels.

Further revascularization. The 5-year actuarial rates of bypass surgery for the PTCA and medically treated groups were $19 \%$ and $16 \%$, respectively. As shown in Fig. 3, the incidence of coronary artery bypass graft surgery after angioplasty was higher than that for medically treated patients $(p=0.002)$. Most bypass procedures in the PTCA group were performed in the first year, and the number of patients requiring surgery in the two groups tended to converge after the second year. In fact most PTCA patients undergoing surgery in the first year had the operation soon after PTCA failed, suggesting a higher "intention to revascularize" in the PTCA group. However, $20.1 \%$ of patients in the PTCA group required further dilatation during follow-up $(15.4 \%$ to the same site, $3.2 \%$ to a different site, and $1.5 \%$ to both the same and different sites). The number of patients in the medically treated group requiring later PTCA was not recorded.

Long-term level of angina. As shown in Table IV, the level of angina was dramatically reduced for patients treated with initial PTCA as compared to medical therapy. This is illustrated in Fig. 4, which shows that $61.4 \%$ of the PTCA patients had no angina after 3 years compared to only $13.9 \%$ of the medically treated patients $(p \leq 0.0001)$.

Long-term employment and activity levels. The relation of therapy to employment status and activity level is shown in Table IV. Although PTCA improved both after correction for differences in baseline variables ( $p \leq 0.0001)$, its influence on these outcomes was not as dramatic as its influence on angina class. The primary benefit of PTCA with regard to employment was seen in the number of patients who were able to continue to work full time (80.1 vs 62.9 at 3 years; $p \leq 0.001$ ), but patients who had already retired for medical reasons seldom $(4.7 \%)$ returned to work after successful PTCA. Activity levels were most improved with PTCA compared to medical treatment in patients who performed moderate or strenuous activity at baseline; $92.4 \%$ vs $50.7 \%$ were still able to perform moderate or strenuous activity at 3 years $(p \leq 0.0001)$ as compared to patients who were sedentary at baseline.

\section{DISCUSSION}

The emergence of PTCA as a relatively safe and apparently effective means of limited coronary revascularization has dramatically altered the way patients with coronary artery disease are treated. However, there are no data to suggest which patients truly benefit from PTCA. The relative efficacies of PTCA and bypass surgery are currently being studied in several large randomized trials, but the role of PTCA versus medical therapy in patients with more limited disease has attracted less attention. In fact, current 


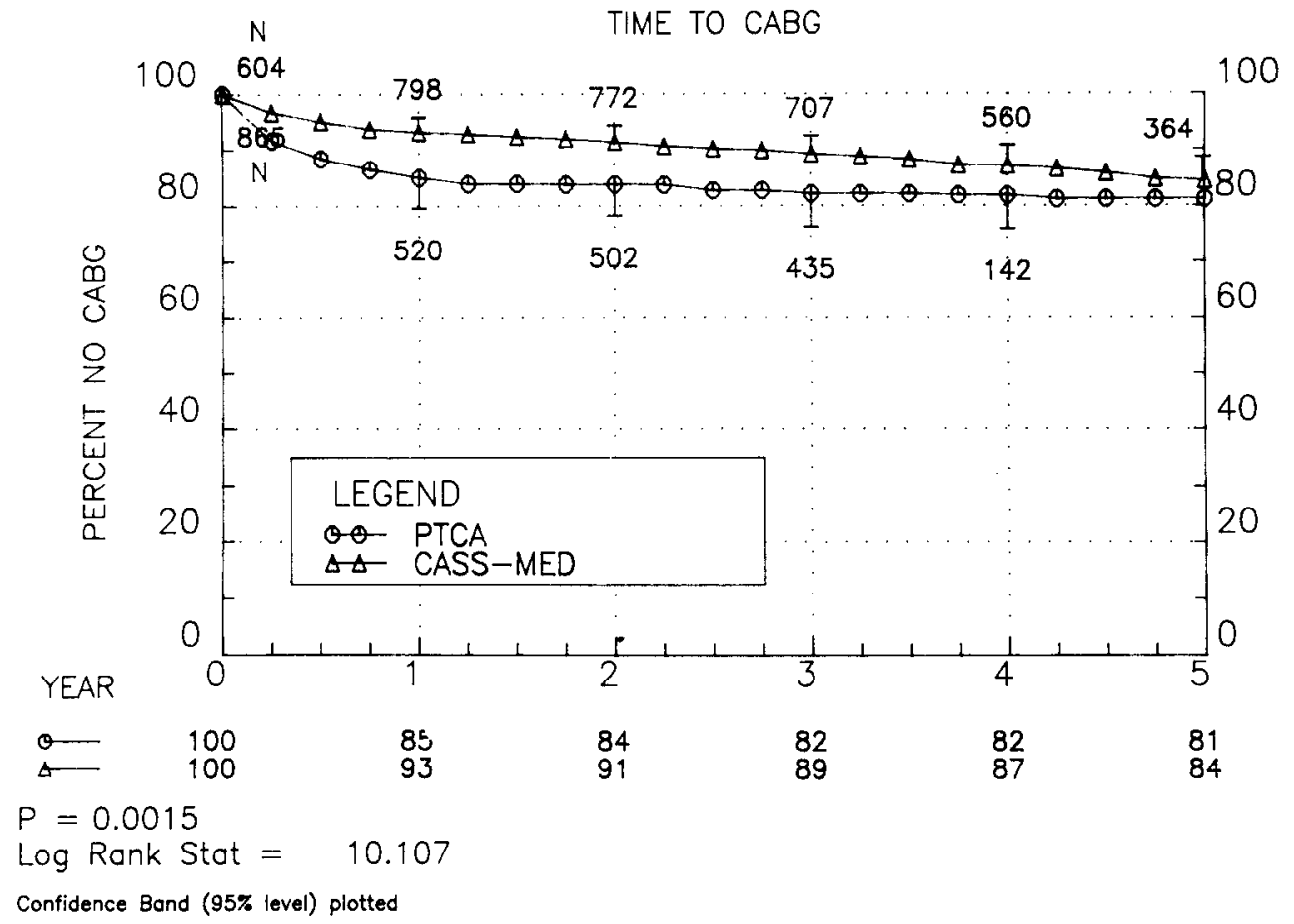

Fig. 3. Life-table analysis of cumulative incidence of bypass surgery after adjustment for differences in maximum LAD percent stenosis, proximal LAD stenosis, and number of diseased vessels.

study designs of trials such as the Veterans Administration trial (250 patients to be randomized between medical therapy and PTCA) will not have the statistical power to detect differences in mortality or rates of infarction between the two treatments. Thus it is highly likely that we will enter the 1990 s without sufficient mortality and infarction data from randomizied trials to adequately assess which patients with limited coronary disease should be offered PTCA.

This study with 1407 patients followed for $\geq 30$ months, although limited by its nonrandomized, nonconcurrent data accrual study design, brings important ancillary data to this area of particular public health interest. It suggests that when the outcome after PTCA was compared with the outcome after medical therapy in patients with single- or doublevessel coronary disease and LAD involvement, PTCA was associated with improved functional status and may have decreased the risk of death and infarction in certain patient subsets. However, PTCA was associated with an increased likelihood of subsequent bypass surgery. Patients likely to have a benefit in survival or risk of infarction from the initial PTCA included those with a left ventricular ejection fraction of less than $50 \%$, those with two-vessel disease, and possibly those with LAD stenoses of $90 \%$ to $99 \%$ severity.
Assessment of outcome of medical treatment in this study compared with that in other studies. The $1 \% /$ year mortality rate for patients with single-vessel and the $1.8 \% / y e a r$ mortality rate for patients with doublevessel disease treated medically in this study were somewhat lower than the $1.5 \%$ to $4.0 \%$ /year mortality rate for single-vessel disease and the $2 \%$ to $7 \%$ year mortality rate for two-vessel disease and LAD involvement reported in other recent series. $4,6,13,15,16,29$ The $2 \%$ yearly incidence of nonfatal myocardial infarction in this series was comparable to that found in the European Cooporative Study and from the randomized portion of the CASS for patients with two-vessel disease.19, 31 Twentyseven percent of patients randomized to medical therapy in the European Cooporative Study "crossed over" to require later bypass surgery because of disabling symptoms. ${ }^{16}$ It was not reported how many of these patients had single- or double-vessel disease. In the randomized portion of the CASS, $10 \%$ of patients with single-vessel and $21 \%$ of patients with doublevessel disease "crossed over" to surgery. This compares with the $16 \%$ rate of later bypass surgery in the medically treated group in this study. Twenty-two percent of the medically treated patients in the European Cooporative Study and $31 \%$ of the randomized medically treated patients in the CASS had no angina after 3 years of medical therapy compared 


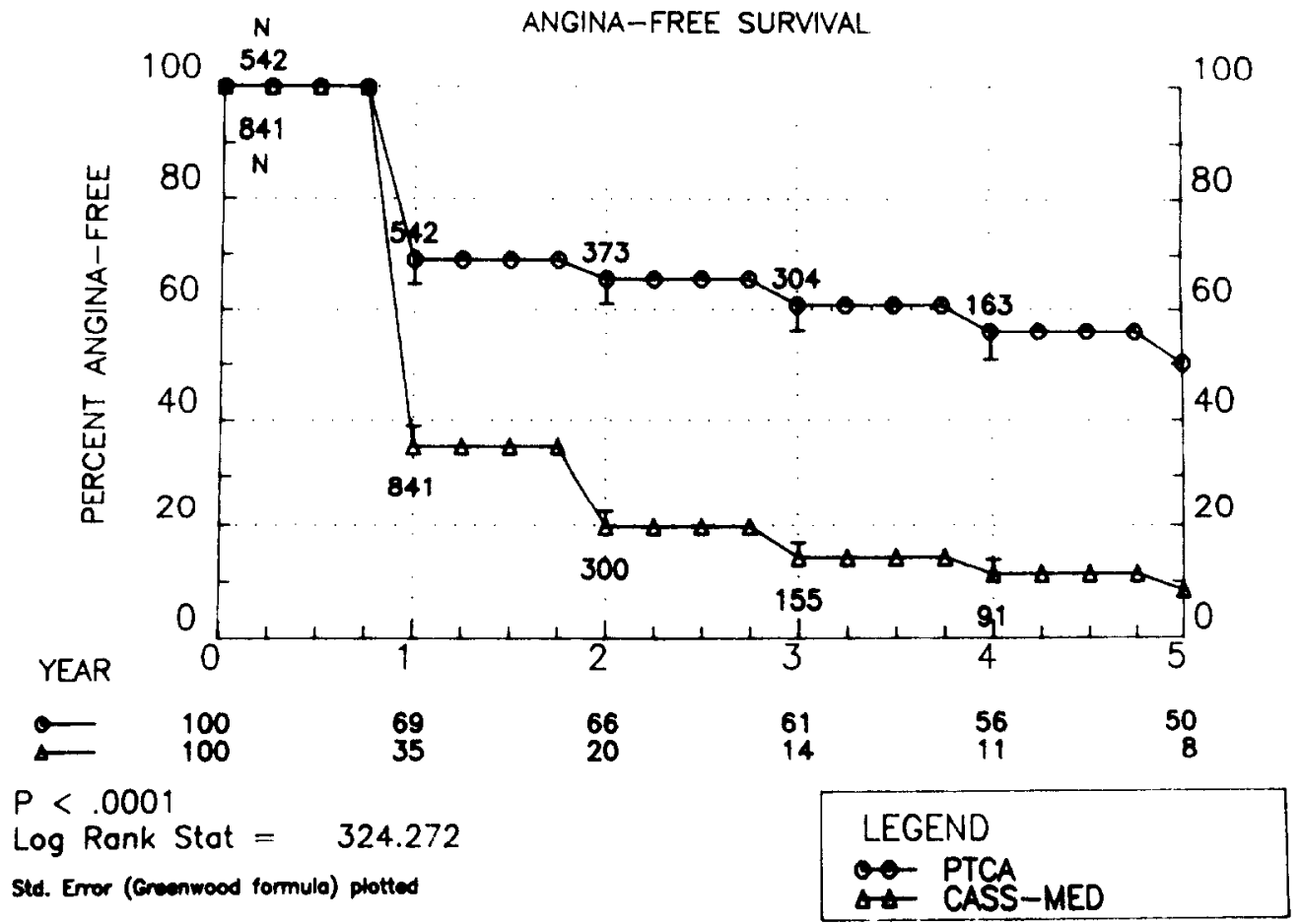

Fig. 4. Life-table analysis of angina-free survival after adjustment for number of diseased vessels, use of beta blockers, baseline Canadian Heart Classification angina level, maximum LAD\% stenosis, use of antiplatelet medications, presence of proximal LAD stenosis $\geq 50 \%$, and sex.

with $14 \%$ of patients in this study. Finally, of the patients randomized to medical therapy in the CASS, $58 \%$ were employed and $75 \%$ could achieve at least mild levels of recreational exertion at 3 years compared to $60 \%$ and $79 \%$, respectively, in this study. ${ }^{32}$

The lower mortality rate and the need for bypass surgery in this study compared with that in other trials may reflect the exclusion of patients with previous anterior myocardial infarction (as this was an intended end point), the lower threshold used to define a "significant" coronary stenosis (see Methods), or the fact that these patients were drawn from a lower risk pool of patients who were intentionally neither treated with bypass surgery nor allowed to be randomized to either medical or surgical therapy. ${ }^{33,34}$ The medically treated patients in this study may have been less severely ill than a sample more fully representative of all medically treated patients with stenoses of the LAD.

Assessment of PTCA outcome. The $91.8 \%$ primary success rate in this series is similar to that in the 1985 National Heart, Lung, and Blood Institute (NHLBI) registry for single (92.2\%) -and double (93.1\%)-vessel disease. ${ }^{35}$ In addition, the incidences of procedure-related death, nonfatal myocardial infarction, and emergency bypass surgery in this series were similar to those reported from the registry. ${ }^{35}$
The late symptom-free status of $61 \%$ of the PTCA patients in this series was similar to the $70 \%$ of patients with primary success from the first NHLBI registry. ${ }^{36}$ The long-term influence of PTCA on employment and tolerance of physical activity has not been previously reported. The results of coronary angioplasty in this study, therefore, appear to be representative of those reported for similar patients.

Results of other studies on medical therapy vs surgical revascularization. The results of the European Cooporative Study and the CASS randomized study for patients similar to those in this study are well known. The European Cooporative Study showed trends toward improved survival in patients with two-vessel disease and proximal LAD involvement, and higher rates of myocardial infarction for surgically treated patients, but did not enroll patients with single-vessel disease or left ventricular ejection fraction less than $50 \% .{ }^{16}$ The CASS found improved survival in surgically treated patients with two-vessel disease with moderate impairment of left ventricular function and at least one proximal obstruction but could not demonstrate a difference if left ventricular function was normal or in the presence of singlevessel disease. ${ }^{17}$ There were no differences in rates of nonfatal myocardial infarction with medical compared to surgical therapy, although neither study 
subgrouped patients by the degree of coronary narrowing. Results of both studies showed improved levels of angina after surgery, but improvements in employment and recreational status could not be demonstrated. ${ }^{16,}, 32$

In this context the results of this study are not surprising, although comparability of outcomes after PTCA and bypass surgery has yet to be demonstrated. In general, revascularization appears to decrease levels of angina and improve survival in patients with moderate to large amounts of potentially jeopardized myocardium or diminished left ventricular function. Reduced risks of myocardial infarction have not been demonstrated, except possibly in patients with very high-grade stenosis who are at highest risk of myocardial infarction. ${ }^{37}$ PTCA appears to increase the number of patients that continue to work, more so than does bypass surgery, perhaps because it has less psychological impact and requires a much shorter period of recuperation away from work. However, as has been noted in other studies, ${ }^{38}$ patients who had been forced to retire because of their cardiac condition before intervention rarely returned to work even after successful PTCA.

Clinical implications. The results of this analysis suggest that PTCA should be considered in patients with single- or double-vessel coronary disease and $\mathrm{LAD}$ involvement as an alternative to medical therapy in four types of patients: those with symptoms refractory to medical treatment, ejection fraction less than $50 \%$, two-vessel involvement, and very highgrade or high-risk LAD stenoses. ${ }^{37,39}$ In view of the increased potential need for bypass surgery after attempted PTCA, asymptomatic or minimally symptomatic patients with single-vessel LAD disease who do not meet the preceding criteria are not likely to benefit appreciably from PTCA. Of course clinical judgement as to the likelihood of successful dilatation ${ }^{40}$ should temper all considerations. Implications regarding the relative merit of PTCA as compared with bypass surgery or the applicability of these results to patients with right coronary or circumflex coronary stenoses or to patients with three-vessel disease cannot be presumed.

Patients with single-vessel proximal LAD involvement, sometimes termed the "widow-maker lesion," 41 are a group of special interest. Although some investigators have found a particularly high mortality rate with medical therapy in this group, $6,10,13,15$ this study could not demonstrate a high mortality rate without, or benefit from, revascularization. This may reflect the fact that although the acute mortality rate with proximal LAD occlusion is high (19\% in the CASS $\left.{ }^{41}\right)$, and although the long-term mortality rate is also increased proportionate to the degree of left ventricular dysfunction, ${ }^{42}$ the overall risk of occlusion with medical therapy is relatively low. ${ }^{43}$ Patients with a high risk of occlusion, such as those with roughened or $90 \%$ to $99 \%$ stenoses, ${ }^{37,39}$ may yet benefit from revascularization.

Limitations. In spite of the relatively large numbers of patients described and the completeness of followup, this study has four major limitations. First, patients in this study were not randomized to treatment. The shortcomings of nonrandomized studies are well recognized, but in their absence a comparison carefully controlling for differences in important baseline variables may be the best alternative. ${ }^{21}$ However, there are limitations on the extent to which Cox analyses can adjust for differences in characteristics between comparison groups and in addition, there may be differences between groups that are not reflected in any of the collected data. Therefore only unique situations justify this type of analysis. These special situations occur when questions of considerable clinical importance are not addressed by the results of randomized clinical trials or large single-institution retrospective studies in which data from all consecutive eligible patients are obtained in an unbiased manner. In this instance, no such data currently exist regarding the comparative long-term outcome after coronary angioplasty and medical therapy for patients with single- and double-vessel disease.

Second, the groups were not treated during exactly the same time period or at the sames sites, patient data were obtained by different investigators, and medical therapy differed between the two groups. Antiplatelet agents have been shown to decrease mortality rates and rates of infarction in patients with unstable angina, ${ }^{43}$ and these agents were prescribed more often in the PTCA group. Beta-blocking agents were used somewhat more commonly in the medically treated group and might be expected to lower the mortality rate in the postinfarction patients in that group. ${ }^{44}$ Calcium channel-blocking agents have been shown to decrease the incidence of nonfatal myocardial infarction only in the first 2 weeks after non-Q wave myocardial infarction ${ }^{45}$ but not in other settings, ${ }^{46}$ so desparities in their use should not be a major obstacle to the interpretation of this study. Results of multivariate analysis performed in this study showed that the use of antiplatelet agents and beta blockers did not protect patients from nonfatal myocardial infarction or death. However, the potential for occult differences in the management of these patients should not be minimized.

Third, the medically treated patients in this study 
appear to have been less severely ill than those in many other series, thus potentially minimizing a possible beneficial effect of PTCA (an intervention that appeared to be somewhat more efficacious in more severely ill patients: double- vs single-vessel disease, proximal vs nonproximal LAD stenosis, ejection fraction $<50 \%$ compared with $\geq 50 \%$, and highgrade vs low-grade stenoses [Tables III and IV]).

Finally, multiple subgroup comparisons were performed for this study and spurious differences may have been created. However, these comparisons were performed between prospectively defined groups, since it is well recognized that patients with LAD stenoses are not a homogeneous group and interventions may differentially affect certain subgroups of patients. Erroneous interpretations can be minimized by being circumspect in the interpretation of borderline significant $p$ values and by correlating these results with those of related clinical studies. Conversely, however, the relatively small numbers of patients in some patient subgroups may have precluded demonstration of clinically important differences in outcome. For example, the power of this study to detect a $30 \%$ reduction in the mortality rate in the group with proximal LAD stenosis, or in the rate of myocardial infarction in the group with $90 \%$ to $99 \%$ stenosis, based on the number of patients studied, outcome with medical therapy, and for $p \leq 0.05$, was only $14 \%$ and $19 \%$, respectively.

Conclusions. Within the limitations of this study the data suggest that PTCA to the LAD improves levels of angina compared with medical treatment at 3-year follow-up, improves survival in patients with ejection fractions of less than $50 \%$, and in patients with two-vessel disease, and may lessen the risk of myocardial infarction in patients with high-grade LAD stenoses. However, initial PTCA was associated with a more frequent use of subsequent bypass surgery. Future randomized trials should include focus on these groups of interest.

We thank Andreas Gruentzig, MD, $\uparrow$ who was adamant in his desire to see the results of PTCA critically analyzed. We also thank Drs. Gruentzig, King, and John S. Douglas, Jr for procedural expertise and Ms. Sheree Wilson, Ms. Vanessa Sims, and Ms. Judy Hanson for their expert assistance in the preparation of this manuscript.

+Deceased.

\section{REFERENCES}

1. Reeves TJ, Oberman A, Jones WB, Sheffield LT. Natural history of angina pectoris. Am J Cardiol 1974;33:423-30.

2. Hammermeister KE, DeRouen TA, Dodge HT. Variables predictive of survival in patients with coronary disease. Selection by univariate and multivariate analyses from the clinical, electrocardiographic, exercise, arteriographic, and quantitative angiographic evaluations. Circulation 1979;59:421-30.
3. Mock MB, Ringquist I, Fisher LD, et al. Survival of medically treated patients in the Coronary Artery Surgery Study (CASS) registry. Circulation 1982;66:562-8.

4. Califf RM, Phillips III HR, Hindman MC, et al. Prognostic value of a coronary artery jeopardy score. J Am Coll Cardiol 1985;5:1055-63.

5. Humphries JO. In: Rahimtoola SH, ed. Coronary bypass sur gery. Philadelphia: FA Davis, 1977:48.

6. Klein LW, Weintraub WS, Agarwal JB, et al. Prognostic significance of severe narrowing of the proximal portion of the left anterior descending coronary artery. Am J Cardiol 1986;58: $42-6$.

7. Kalbfleisch H, Horst W. Quantitative study on the size of coronary artery supplying areas postmortem. AM HEART J 1977;94:183-92

8. Bruschke AVG, Proudfit WL, Sones FM. Progress study of 590 consecutive nonsurgical cases of coronary disease followed 5-9 years. Circulation 1973;47:1147-53.

9. Burggraf GW, Parker JO. Prognosis in coronary artery disease. Angiographic, hemodynamic, and clinical factors. Circulation $1975 ; 51: 146-56$.

10. Webster JS, Moberg C, Rincon G. Natural history of severe proximal coronary artery disease as documented by cineangiography. Am J Cardiol 1974;33:195-200.

11. Califf RM, Tomabechi Y, Lee KL, et al. Outcome in one-vessel coronary artery disease. Circulation 1983:67:283-90.

12. Kumpuris AG, Quinones MA, Kanon D, Miller RR. Isolated stenosis of left anterior descending or right coronary artery: relation between site of stenosis and ventricular dysfunction and therapeuetic implications. Am J Cardiol 1980;46: 15-20.

13. Brooks N, Cattel M, Jennings $K$, Balcon $R$, Honey M, Layton C. Isolated disease of left anterior descending coronary artery. Angiocardiographic and clinical study of 218 patients. $\mathrm{Br}$ Heart J 1982;47:71-7.

14. Leong $K$, Jones RH. Influence of the location of left anterior descending coronary artery stenosis on left ventricular function during exercise. Circulation 1982;65:109-14.

15. Samaja JK, Connor MJ, Tribble R, et al. Natural history of left anterior descending coronary artery obstruction: significance of location of stenoses in medically treated patients. Clin Cardiol 1985;8:415-22.

16. European Coronary Surgery Group. Long-term results of prospective randomized study of coronary artery bypass surgery in stable angina pectoris. Lancet 1982;2:1173-80.

17. Mock MB, Fisher LD, Holmes DR, et al. Comparison of effects of medical and surgical therapy on survival in severe angina pectoris and two-vessel coronary artery disease with and without left ventricular dysfunction: a coronary artery surgery study registry study. Am .J Cardiol 1988;61:1198-1203.

18. CASS principal investigator and their associates: Coronary artery surgery study (CASS): a randomized trial of coronary artery bypass surgery. Circulation 1983;68:939-50.

19. CASS principal investigators and their associates. Myocardial infarction and mortality in the coronary artery surgery study (CASS) randomized trial. N Engl J Med 1984;310:750-8.

20. Gruentzig AR, Hollman J. Improved primary success rate in transluminal coronary angioplasty using a steerable guidance system [Abstract]. Circulation 1982;66(suppl 2):330.

21. Hartzler GO, Rutherford BD, McConahay DR. "Non-investigational" experience with percutaneous transluminal coronary angioplasty in a clinical center [Abstract]. Am J Cardiol 1982;49:916.

22. Meier B, Gruentzig AR. Learning curve for percutaneous transluminal coronary angioplasty: skill, technology or patient selection. Am J Cardiol 1984;54:918.

23. Meier B, Gruentzig AR, Siegenthaler WE, Schlumpf $M$. Long-term exercise performance after percutaneous transluminal coronary angioplasty and coronary artery bypass grafting. Circulation 1983;68:796.

24. Califf RM, Pryor DB, Greenfield JC. Beyond randomized clinical trials: applying clinical experience in the treatment of 
patients with coronary artery disease. Circulation 1986; 74:1191.

25. Anderson HV, Roubin G, Leimgruber P, Douglas J, King S, Gruentzig AR. Primary angiographic success rates of percutaneous transluminal coronary angioplasty. Am $\mathrm{J}$ Cardiol 1985;56:712-17.

26. Principal Investigators of CASS and their Associates. National Heart, Lung, and Blood Institute Coronary Artery Surgery Study. Circulation 1981;63(suppl I):1-81.

27. Gruentzig AR. Technique of percutaneous transluminal coronary angioplasty. In: Hurst JW, ed. The heart. New York: McGraw-Hill, 1982:1904-15.

28. Blackburn H, Keys A, Simonson E, Rautaharju P, Punsar S. The electrocardiogram in population studies: a classification system. Circulation 1960;21:1160-75.

29. Chaitman BR, Davis K, Fisher LD, et al. A life table and Cox regression analysis of patients with combined proximal left anterior descending and proximal left circumflex coronary artery disease: non-left main equivalent lesions (CASS). Circulation 1983;68:1163-70.

30. Califf RM, Tomabechi Y, Lee K, et al. Outcome in one-vessel coronary artery disease. Circulation 1983;67:283-90.

31. Varnauskas E. Myocardial infarction in the randomized European Coronary Surgery Study. Circulation 1983;68:JII-393.

32. CASS principal investigators and their associates. Coronary artery surgery study (CASS): a randomized trial of coronary artery bypass surgery. Quality of life in patients randomly assigned to treatment groups. Circulation 1983;68:951-60.

33. Vlietstra R, Kronmal R, Frye R, Seth A, Tristani F, Killip T. Factors affecting the extent and severity of coronary artery disease in patients enrolled in the coronary artery surgery study. Arteriosclerosis 1982;2:208-15.

34. CASS principal investigators and their associates. Coronary artery surgery study (CASS). A randomized trial of coronary artery bypass surgery. Comparability of entry characteristics and survival in randomized patients and non-randomized patients meeting randomization criteria. J Am Coll Cardiol 1984;3:114-28.

35. Detre K, Holubkou R, Kelsey S, et al. Percutaneous transluminal coronary angioplasty in $1985-1986$ and $1977-1981$. N Engl J Med 1988;318:265-70.

36. Kent K, Cowley M, Kelsey C, Costigan T, Detre K. Long-term follow-up of the NHLBI-PTCA Registry. Circulation 1986;74:II-280.

37. Ellis S, Alderman E, Cain K, Fisher L, Sanders W, Bourassa $M$. Prediction of risk of anterior myocardial infarction by lesion severity and measurement method in the left anterior descending coronary distribution. A CASS registry study. J Am Coll Cardiol 1988;11:908-16.

38. Russell RO, Abi-Mansour P, Wenger NK. Return to work after coronary bypass surgery and percutaneous transluminal coronary angioplasty: issues and potential solutions. Cardiology 1986;73:306-11.

39. Ellis S, Alderman E, Cain K, Wright A, Bourassa M, Fisher L. Morphology of left anterior descending territory lesions as a predictor of anterior myocardial infarction: a CASS registry study. J Am Coll Cardiol (Accepted for publication)

40. Ellis S, Roubin G, King S, Douglas G, Weintraub W, Cox W. Angiographic and clinical predictors of acute closure after native vessel coronary angioplasty. Circulation 1988;77:372-9.

41. Holmes DR, Fisher L, Mock M, McConney M, Russell R, Schaff HV. Isolated proximal left anterior descending (LAD) stenoses: widow-maker, fact or fancy. An observational CASS registry study. Circulation 1985;72(suppl III):458.

42. Sanz G, Castaner A, Betriu A, et al. Determinants of prognosis in survivors of myocardial infarction. A prospective clinical angiographic study. N Engl J Med 1983;306:1065-70.

43. Lewis H, Davis J, Archibald D, et al. Protective effects of aspirin against acute myocardial infarction and death in men with unstable angina. Results of a Veterans Administration and Cooporative study. N Engl J Med 1983;309:396-403.

44. Beta-blocker Heart Attack Trial Research Group. A random- ized trial of propranolol in patients with acute myocardial infarction. I. Mortality results. JAMA 1982;247:1707-14.

45. Gibson $R$, Boden $W$, Theroux $P$, et al. Diltiazem and reinfarction in patients with non-Q-wave myocardial infarction. $R e$ sults of a double-blind, randomized, multicenter trial. N Engl J Med 1986;315:423-9.

46. The Danish Study Group on Verapamil and acute myocardial infarction. Verapamil and acute myocardial infarction. Eur Heart J 1984;5:516-28.

\section{APPENDIX I}

Cooperating Clinical Sites

University of Alabama in Birmingham: William J. Rogers, MD,* Richard O. Russell, Jr., MD, Albert Oberman, MD, and Nicholas T. Kouchoukos, MD. Albany Medical College: Eric D. Foster, MD, ${ }^{*}$ Julio A. Sosa, MD,* Joseph T. Doyle, MD, Martin F. McKneally, MD, Joseph B. McIlduff, MD, Harry Odabashian, MD, and Thomas M. Older, MD. Boston University: Thomas Ryan, $\mathrm{MD},{ }^{*}$ David Faxon, MD, Laura Wexler, MD, Robert L. Berger, MD, Donald Weiner, MD and Carolyn H. McCabe, BS. Loma Linda University: Joan Coggin, MD.* Marshfield Medical Foundation, Inc. and Marshfield Clinic: William Myers, MD,* Richard D. Sautter, MD,* John N. Browell, MD, Dieter M. Voss, MD, and Robert D. Carlson, MD. Massachusetts General Hospital: J. Warren Harthorne, MD, ${ }^{*}$ W. Gerald Austen, MD, * Robert Dinsmore, MD, Frederick Levine, MD, and John McDermott, MD. Mayo Clinic and Mayo Foundation: Robert L. Frye, MD, ${ }^{*}$ Bernard Gersh, MD, David R. Holmes, MD, Michael B. Mock, MD, Hartzell Schaff, MD, and Ronald E. Vlietstra, MD. Miami Heart Institute: Arthur J. Gosselin, MD,* Parry B. Larsen, MD, and Paul Swaye, MD. Montreal Heart Institute: Martial G. Bourassa, MD,* Claude Goulet, MD, and Jacques Lesperance, MD. New York University: Ephraim Kaiser, MD, ${ }^{*}$ and Michael Schloss, MD. St. Louis University: George Kaiser, MD, ${ }^{*}$ J. Gerard Mudd, MD,* Robert D. Wiens, MD, Hendrick B. Barner, MD, John E. Codd, MD, Dennis H. Tyras, MD, Vallee L. Willman, MD, and Bernard R. Chaitman, MD. St. Luke's Hospital Center: Harvey G. Kemp, Jr., MD, ${ }^{*}$ and Airlie Cameron, MD. Stanford University: Edwin Alderman, MD, * Francis H. Koch, MD, Paul R. Cipriano, MD, James F. Silverman, MD, and Edward B. Stinson, MD. Medical College of Wisconsin: Felix Tristani, MD, ${ }^{*}$ Harold L. Brooks, MD, ${ }^{*}$ and Robert J. Flemma, MD. Yale University: Lawrence S. Cohen; MD, * Rene Langou, MD, Alexander S. Geha, MD, Graeme L. Hammond, MD, and Richard K. Shaw, MD.

*Principal Investigator. 
Central Electrocardiographic Laboratory

University of Alabama: L. Thomas Sheffield, MD,* David Roitman, MD, and Carol Troxell, BS.

\section{Coordinating Center}

University of Washington: Kathryn Davis, $\mathrm{PhD}$, Kevin Cain, PhD, Lloyd Fisher, PhD, Mary Jo Gillespie, MS, J. Ward Kennedy, MD, and Richard Kronmal, $\mathrm{PhD}$.
Chairman of the Steering Committee Thomas Killip, MD, Beth Israel Medical Center

National Heart, Lung, and Blood Institute Thomas Robertson, MD, Eugene R. Passamani, MD, and Peter Frommer, MD.

*Principal Investigator.

\section{Survival patterns in clinical and angiographic subsets of medically treated patients with combined proximal left anterior descending and proximal left circumflex coronary artery disease (CASS)}

Baseline, clinical, and angiographic features of 1014 Coronary Artery Surgery Study (CASS) registry patients with combined proximal left anterior descending and proximal left circumflex coronary disease were examined to define determinants of prognosis in this clinical high-risk patient subset. A stepwise Cox regression analysis identified congestive heart failure score, left ventricular contraction score, mitral regurgitation, age, and digitalis usage as independent variables predictive of 8-year survival. When patients were stratified by left ventricular contraction score, the 8-year survival rate was $62 \%, 49 \%$, and $19 \%$, respectively, for patients with a left ventricular score of 5 to 9,10 to 14 , and $\geq 15(p<0.0001)$. The presence of a stenosis $\geq 70 \%$ in the right coronary artery was associated with worse survival $(47 \%$ versus $54 \%$ at 8 years; $p=0.051$ ). In conclusion, the diagnosis of combined proximal left anterior descending and left circumflex coronary artery disease represents a large prognostic spectrum that needs to be considered when counselling individual patients. (AM HEART J 1989;118:220.)

Paul M. Zack, MD, Bernard R. Chaitman, MD, Kathryn B. Davis, PhD, George C. Kaiser, MD, Robert D. Wiens, MD, Grace Ng, BS, and the CASS Investigators. St. Louis, Mo.

Most large-scale investigations that have examined the natural history of coronary artery disease have classified the angiographic extent of disease as one-,

From the Department of Medicine, Division of Cardiology, St. Louis University School of Medicine.

The collaborative study in coronary artery surgery is funded by the National Heart, Lung, and Blood Institute of the National Institutes of Health, Bethesda, Md.

Received for publication Feb. 10, 1989; accepted Apr. 1, 1989.

Reprint requests: Bernard R. Chaitman, MD, St. Louis University Hospital, 3635 Vista Ave. at Grand Blvd., St. Louis, MO 63110-0250. two-, three-vessel and left main coronary artery disease. ${ }^{1-4}$ There has been considerable interest in the natural history of another angiographically identifiable classification: combined proximal left anterior descending and proximal left circumflex coronary artery disease (combined proximal left coronary artery disease [CPLCAD])..$^{5-12}$ It has been suggested that the prognosis of medically treated patients with CPLCAD is similar to that of patients with left main coronary artery disease, and CPLCAD has sometimes been termed a "left main equivalent." 